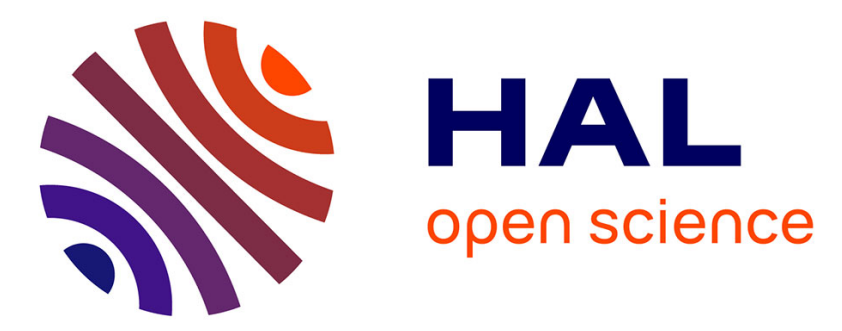

\title{
Competition vs. communication: An experimental study on restoring trust
}

Vivian Lei, David Masclet, Filip Vesely

\section{To cite this version:}

Vivian Lei, David Masclet, Filip Vesely. Competition vs. communication: An experimental study on restoring trust. Journal of Economic Behavior and Organization, 2014, 108, pp.94-107. 10.1016/j.jebo.2014.09.001 . halshs-01074083

\section{HAL Id: halshs-01074083 \\ https://shs.hal.science/halshs-01074083}

Submitted on 13 Oct 2014

HAL is a multi-disciplinary open access archive for the deposit and dissemination of scientific research documents, whether they are published or not. The documents may come from teaching and research institutions in France or abroad, or from public or private research centers.
L'archive ouverte pluridisciplinaire HAL, est destinée au dépôt et à la diffusion de documents scientifiques de niveau recherche, publiés ou non, émanant des établissements d'enseignement et de recherche français ou étrangers, des laboratoires publics ou privés. 


\title{
Competition vs. Communication: An Experimental Study on Restoring Trust ${ }^{\dagger}$
}

\author{
Vivian Lei ${ }^{\mathrm{a},{ }^{,}}$, David Masclet ${ }^{\mathrm{b}}$, Filip Vesely ${ }^{\mathrm{c}}$
}

\begin{abstract}
Trust is fragile. It is hard to build but easy to destroy. In this paper, we explore the fragility of trust in a stylized laboratory environment. We ask whether transgression outside a direct sendand-return relationship destroys trust and, if so, whether a competition against outsiders or an apology for misdeeds helps restore it. We find that transgression significantly reduces trust and that the broken trust can be greatly restored by group competition. Communication via an apology, impersonal or not, has an insignificant impact. By contrast, offering explanations for misbehavior is as effective as group competition.
\end{abstract}

Keywords: experiments; trust restoration; group competition; communication

JEL Codes: C90, C92, D70, D74, D80

\footnotetext{
$\dagger$ We would like to thank Elven Priour for programming for the experiment. Financial support from the Agence Nationale de la Recherche (ANR-08-JCJC-0105-01, "CONFLICT” project) is gratefully acknowledged. We also thank Juan Cardenas, Gary Charness, David Cooper, Tor Eriksson, Peter Kuhn, Stephane Robin, Marie-Claire Villeval, Marc Willinger, seminar participants at Academia Sinica, the 2011 EMIR Workshop in Lyon, and the 2011 French Experimental Economics Association Annual Meeting in Schoelcher-Martinique for their helpful comments.

${ }^{a}$ Department of Economics, University of Wisconsin-Milwaukee, Milwaukee, WI 53201, U.S.A

* Corresponding author. Tel.: +1 4142296494.

E-mail addresses: vlei@uwm.edu (V. Lei),david.masclet@univ-rennes1.fr (D. Masclet), vesely@uwm.edu (F.

Vesely).

${ }^{\mathrm{b}}$ Department of Economics, University of Rennes, Rennes, France.

${ }^{c}$ Department of Economics, University of Wisconsin-Milwaukee, Milwaukee, WI 53201, U.S.A.
} 
"Trust is like a vase, once it's broken, though you can fix it the vase will never be the same again." - Unknown author

\section{Introduction}

Trust is the lubricant of all relationships. It makes relationships work more cohesively and efficiently. In recent years, a vast majority of experimental studies have been devoted to identifying factors that would facilitate such a virtue. Allowing players to observe their partners' past history (Bohnet et al., 2005; Bolton et al., 2004, 2005, Brown and Zehnder, 2007; Charness et al., 2011; Duffy et al., 2013; Keser, 2003) and to have pre-play communication (Ben-Ner and Putterman, 2009; Ben-Ner et al., 2011; Buchan et al., 2006; Charness and Dufwenberg, 2006; Glaeser et al., 2000; Malhotra and Murnighan, 2002; Servatka et al., 2011) are just two of the many factors that are found to be able to elicit more trust from newly matched counterparts.

Yet, trust is also fragile. The vulnerability of trust has not escaped public attention in recent years after the breakout of several government and corporate scandals. A Gallup poll conducted in September 2013 indicates that Americans' trust in the federal government is almost in its all-time low. ${ }^{1}$ The latest World Values or General Social Survey suggests that only one-third of Americans, versus one-half in the early 1970s, say most people can be trusted. Trust is on the decline, but the literature has largely ignored it. Almost all the focus in the economics literature has been on the initial trust formation than on trust restoration in the aftermath of an infringement. Can trust be successfully recovered after a violation? Is an instrument shown to be effective in eliciting initial trust equally powerful in rebuilding broken trust? In response to the alleged US eavesdropping of her cell phone, German Chancellor Angela Merkel firmly asserted that words would not be sufficient to rebuild the trust between

\footnotetext{
${ }^{1}$ See Jones (2013) for more specific information. A similar decline pattern is also observed in some of the EU countries (Manchin, 2013).
} 
the two partners. ${ }^{2}$ A reaction like this prompts us to believe that fixing a broken relationship is an entirely different task and that revisiting the tactics shown to be effective in promoting initial trust is as important as exploring new ones. ${ }^{3}$

It is worth noting that there does exist a small but growing body of work in the literature of organizational management that tackles trust violation and restoration (see, for example, Dirks, Kim, Ferrin, and Cooper, 2011; Ferrin, Kim, Cooper and Dirks, 2007; Kim, Dirks, Cooper, and Ferrin, 2006; Kim, Ferrin, Cooper and Dirks, 2004; Schweitzer, Hershey, and Bradlow, 2006). With very few exceptions, this body of work all seems to employ the same laboratory setting in which participants assume the role of a manager who is in charge of hiring. They first watch a videotaped job interview in which an applicant is presented with an allegation of a trust violation in her last job, and then rate their trust in the applicant. Depending on the treatment, different version of the interview is presented to participants. For instance, to see if apologies affect trust, participants are asked to complete a questionnaire after watching a video clip in which the job candidate responds to the allegation with an apology. In addition to apologies, denials and promises have also been investigated in these studies. ${ }^{4}$

Instead of using questionnaires, Schweitzer et al. (2006) adopt a variant of the investment game of Berg et al. (1995) in which financial incentives are determined directly by participants' decisions. ${ }^{5}$ They investigate how deception and untrustworthiness affect trust and if communication in various forms helps restore it. Schweitzer et al. find that trust can be

\footnotetext{
${ }^{2}$ A survey conducted by public broadcaster ARD and Die Welt daily in November 2013 indicated that Germans' confidence in the US as a trustworthy partner plunged to $35 \%$ following the scandal.

${ }^{3}$ See Kim et al. $(2004,2006)$ for discussions on why trust repair may differ not only quantitatively but also qualitatively from initial trust development.

${ }^{4} \mathrm{~A}$ few researchers have also started investigating the impact of substantive acts like penance, regulation, and reparation on rebuilding trust (e.g., Desmet et al., 2011; Dirks et al., 2011; Lount et al., 2008).

${ }^{5}$ Dirks et al. (2011) use both settings to investigate the effects of penance and regulation.
} 
easily destroyed but, as long as deception is not involved, it can also be rebuilt. Among the various communication options, apologies are the least effective tool to rebuild trust.

To compare these two different approaches used in the literature, we argue that the former has an advantage over the latter in that it resembles more real-world situations, but that the use of a hypothetical scenario in which a violation does not directly involve participants may subdue the impact of the infringement and thus misrepresent the (relative) effectiveness of different means to repair trust. As a result, we follow Schweitzer et al. and adopt an incentive-based experiment to study how to best restore broken trust. But unlike Schweitzer et al. in which deception is used not only as a treatment but also as a design feature, we avoid such a practice so that we don't contaminate the decision-making environment and distort the incentives facing our human subjects. ${ }^{6,7}$ In other words, our first contribution to the literature concerns the methodology we use to approach the issues on trust violation and restoration: our incentive-based, deception-free experiment offers a more reliable and transparent framework in which the impact of different infringements and the effectiveness of various trust remedies can be evaluated more systematically.

Our second contribution concerns the investigation of a new trust remedy that has never been explored in the literature on trust repair. Motivated by the diversionary war theory in political science, we introduce competition between two rival groups as a way to alleviate the internal tension and, hopefully, expedite the process of reconciliation. Competing against outsiders has been shown to be effective in eliciting intra-group cooperation in public good or social dilemma games (see, for instance, Bornstein et al., 1990; Bornstein and Erev, 1994; Brown, 2000; Erev et al., 1993; Reuben and Tyran, 2010; Tan and Bolle, 2007). Yet, its effect

\footnotetext{
${ }^{6}$ In Schweitzer et al, players were led to believe that they were matched with human subjects, whereas it was the experimenter who assumed the role of the trustee and manipulated what message, if any, each trustor would receive. In our study, both roles were played by human subjects.

${ }^{7}$ See, for example, Ortmann and Hertwig (2002) for the negative impact of deceiving human subjects in an experiment.
} 
on repairing broken trust is completely unknown. And even if one can argue that trust is positively correlated with cooperation, that trust repair is a more challenging task than initial trust elicitation justifies an investigation of group competition's remedial effect.

Lastly, our paper contributes to the literature by offering a direct comparison between the effectiveness of the new trust remedy and that of apologies in restoring trust. As we mention above, verbal tactics such as apologies have been studied rather extensively using hypothetical scenarios and questionnaires. Therefore, it is important for us to validate some of these findings in the literature using our incentive-based, deception-free experiment. Also note that the effectiveness of a trust remedy often depends on the type of violation (see, for example, Dirks et al., 2011; Ferrin et al., 2007; Kim et al., 2004, 2006). Therefore, it is difficult for us to draw an accurate conclusion about the relative remedial effect simply based on the literature related to the initial trust development. Our paper, to our knowledge, is the first study to provide such a comparison.

The specific research questions we ask are as follows: Would transgression such as stealing damage trust? If so, are competing against an outsider and communication between group members equally effective in restoring it? To answer these questions, we design an experiment in which a partner matching protocol is used throughout six decision rounds. A decoding task is employed in round 1 to determine subjects' initial earnings and the roles they play in a trust or investment game in rounds 2,4 , and 6 . Transgression is allowed in round 3. Specifically, players who receive smaller earnings in round 1 and thus play trustees in round 2 are given an opportunity to steal their partners' earnings made through the decoding task. In round 5, a trust remedy, either group competition or communication, is employed to help recover any lost trust. In the Group Competition treatment, the computer randomly matches two pairs to compete for a monetary prize. In the Communication treatment, the trustee is allowed to send a pre-programmed message to apologize to the trustor. Finally, we include 
two baseline treatments to control for wealth effects as well as to tease out the impact of repeated matching.

As reported in Section 4, we find that an intentional act of stealing that reverse the relative income status between the trustor and the trustee significantly undermines trust. We also find that group competition is an effective tool to rebuild a broken relationship and that communication via a preprogrammed message has an insignificant impact on trust restoration. To test the robustness of the communication effect, we include a second communication treatment called Free-Form Communication in which a private chat window is open for two minutes in round 5 for partners to send text messages to each other. We find that personalized apologies have a positive but insignificant impact on rebuilding broken trust. Explanations for misbehavior, on the other hand, are as effective as group competition. Therefore, depending on the content and how it is conveyed, communication can be indeed an effective tool to restore trust.

The rest of our paper is organized as follows. Section 2 describes the experimental design and procedures. Section 3 discusses the hypotheses that we propose for evaluation. Section 4 reports the results from the Group Competition, Communication, and the baseline treatments. Section 5 provides a robustness check for the communication effect. Section 6 concludes the paper.

\section{The Experiment}

The experiment consisted of four treatments and fifteen sessions conducted at the CREM-CNRS (LABEX) institute of the University of Rennes 1, France. A total of 300 undergraduate students majored in business, economics, law, engineering, medicine or literature were recruited via the ORSEE software (Greiner, 2004). Some of the subjects may have participated in economics experiments before, but none had any experience in 
experiments similar to ours. No individual participated in more than one session of this study. On average, sessions lasted about 90 minutes including initial instruction period and payment of subjects. Subjects earned an average of 16.75 Euros, including a show-up fee of 2 Euros. ${ }^{8}$ The experiment was computerized using the Z-tree software package (Fischbacher, 2007).

The four treatments were the Group Competition, the Communication, the Exogenous Baseline and the Endogenous Baseline treatments. There were five, four, three and three sessions in the four treatments respectively. Each session, regardless of the treatment, was divided into six rounds. Subjects were randomly matched into pairs at the beginning of the session and played with the same partners throughout all six rounds. Instructions were given only at the beginning of each round. Summary information about each of the fifteen sessions is given in Table 1.

[Table 1: About Here]

\subsection{The Group Competition Treatment}

In round 1 of the Group Competition treatment, an entitlement technique was used in that players had two minutes to perform a decoding task and that the relative performance between two matched counterparts determined their initial earnings and the roles they played for the rest of the experiment. The entitlement technique was chosen so that stealing could have a more devastating effect on trust, which in turn makes the investigation of trust remedies more meaningful.

The decoding task adopted in our study was the same as that in Charness et al. (2013). That is, subjects were asked to identify, from a grid of letters, the numerical number corresponding to a specific alphabet letter shown on their computer screen (see Fig. 1 for the

\footnotetext{
${ }^{8}$ The experimental currency, called ECU, was converted to Euros at a predetermined conversion rate of 4 ECUs $=1$ Euro.
} 
screenshot). A new question with a different grid of letters would not appear until after the current one was answered correctly. After two minutes had elapsed, the computer displayed a summary screen of two matched counterparts' performances. The person who answered more (less) questions correctly was then awarded 21 (9) ECUs and assigned a role of Player A (B). The roles remained fixed throughout the rest of the experiment.

[Fig. 1: About Here]

In round 2, the trust game by Berg et al. (1995) was introduced using a strategy method. Participants first received 10 ECUs as their cash endowment. Player A was given an opportunity to transfer none, some, or all of his cash endowment to his paired Player B. All money passed on was tripled before it reached Player B. Simultaneously, Player B was asked to indicate how much, if any, she wished to return. Note that Player B had no information about how much she would receive from Player A at this point. Therefore, we asked Player B to specify the amount of money she wished to return given each of the following possibilities: 3 ECUs $(1$ ECU * 3), 6 ECUs (2 ECUs * 3), 9 ECUs $(3$ ECUs * 3), .., and 30 ECUs $(10$ ECUs * 3). Once these decisions were made, the computer calculated players' period earnings based on the following formulas: Player A's period earnings $=10$ ECUs (cash endowment) the amount sent + the amount returned, and Player B's period earnings $=10$ ECUs (cash endowment) $+3 *$ the amount sent - the amount returned. Players' decisions and their respective period earnings in the trust game were not revealed until the end of the experiment in order to prevent the pass and return decisions from feeding back on each other via repeated matching and thus contaminating the impact of transgression and trust remedy.

In round 3, we allowed the poorer Player B to steal or "redistribute" $0,5,10,15$, or 20 ECUs from Player A's 21 ECUs earned in round $1 .{ }^{9}$ We imposed no cost on stealing. Player A had no decision to make in this round. The amount of redistribution was revealed to Player

\footnotetext{
${ }^{9}$ We used more neutral wording such as "reduce player A's payoff" rather than "steal" in the instructions.
} 
A at the end of round 3. And to examine if B's misdeed undermines trust, the same trust game as described above was played again in round 4. As in round 2, players were not informed about each other's decision and earnings in round 4 until the end of the experiment.

Finally, in rounds 5 and 6 , we study if a group competition helps reestablish trust. At the beginning of round 5, the computer randomly matched two pairs to compete for a prize of 40 ECUs that would be equally divided between the winning team's members. The competition required them to perform the same decoding task as in round 1. Communication between two partners was not allowed. After two minutes had elapsed, the computer displayed a summary screen that allowed each contestant to identify not only his performance relative to his partner's, but also his group performance relative to the other group's. The group with more correct answers in total won the prize. In case there was a tie, a random draw was used to break the tie. The group competition round was followed by a trust game in round 6.

\subsection{The Communication Treatment}

The Communication treatment was similar to the Group Competition treatment except that, in round 5, a structured one-way communication was introduced as the trust restoring instrument. Communication was one-way because only Player B was allowed to send a message. It was structured because the message was pre-programmed to be either "I apologize," or "I don't apologize." Player A received the message instantly once the button associated with one of the two messages was clicked. Player B could also opt out from communication by simply clicking the button of "No message sent."

\subsection{The Exogenous Baseline Treatment}


To investigate whether or not an intentional act of stealing undermines trust, we designed a baseline treatment in which Player Bs' stealing decisions in round 3 were replaced by exogenous, random income redistributions from As to Bs. Note that these exogenous, random redistributions were executed based on the distribution of Player Bs' stealing decisions in the previous two treatments. This procedure was, however, not explained to subjects.

To control for wealth effects, 40 ECUs that was equivalent to the winning prize in the Group Competition treatment, was also randomly awarded to half of the matches in round 5 of the Exogenous Baseline treatment.

\subsection{The Endogenous Baseline Treatment}

Since the income redistributions in the Exogenous Baseline treatment were completely exogenous, trust destruction that was associated with transgression should not exist. As a result, the Exogenous Baseline treatment was not appropriate for investigating the effectiveness of trust remedies. A second baseline treatment, called the Endogenous Baseline treatment, was then introduced to tackle this issue. In the Endogenous Baseline, the poorer Player B in each match was given an opportunity in round 3 to steal some money from his or her matched Player A. Otherwise, the Endogenous Baseline was exactly the same as the Exogenous Baseline in that they both controlled for wealth effects but offered no trust remedy to rebuild the relationship.

\section{Hypotheses}

Assuming that players are self-interested, the two-stage trust game by Berg et al. (1995) has a unique subgame perfect Nash equilibrium which predicts that Player B (the trustee) will return nothing back in stage 2 and, knowing this, Player A (the trustor) will send 
nothing in stage 1 . The fact that the trust game is repeated three times in our experiment should not change the theoretical prediction. Competing against a rival group or having cheap talk between two group members also should not affect the equilibrium behavior that is motivated solely by self-interest. Yet, contrary to the theoretical prediction, numerous studies have shown that trustors transfer a nontrivial amount to their paired trustees (see, for example, Berg et al., 1995; Burk et al., 2003; Chaudhuri and Gangadharan, 2003; Croson, and Buchan, 1999; Willinger et al., 2003). As a result, we expect that subjects in our experiment would behave similarly.

Having said that, we hypothesize that stealing would have a devastating effect on the amount sent. We propose this hypothesis based on the following reasons. First, integrity, defined as honesty and moral character, has been identified as an important trust determinant by, for example, Butler (1991), Butler and Cantrell (1984) and Gabarro (1978). As a result, the act of stealing could discourage the trustor from extending the benefit of the doubt to the "dishonest" trustee. Second, stealing may trigger negative emotions such as anger which, according to Dunn and Schweitzer (2005) and Lewicki et al. (2006), could damage trust significantly. Based on these reasons, we formalize our hypothesis in the following.

\section{HyPOTHESIS 1: An intentional act of stealing undermines trust.}

Our second hypothesis concerns the effectiveness of group competition in rebuilding trust. We expect that the existence of an external threat would alleviate the internal tension and thus facilitate the process of trust restoration. This hypothesis is partially motivated by the diversionary theory of war in political science which argues that, facing a potential threat from a rival group, the in-group/out-group distinction could help transform an internal conflict into a feeling of unity among in-group members (Coser, 1956; Simmel, 1956). The diversionary theory has been used to explain the motivations behind, for example, the French Revolutionary Wars in 1792 (Blanning, 1986), the Russo-Japanese War in 1904 (Langer, 
1969; Lebow, 1981; White, 1964), and, most notably, the use of military force by American presidents to exploit the so-called rally-round-the-flag effect during domestic crises (see, for example, Mueller, 1973; Kernell, 1978; Lee, 1977; MacKuen, 1983; Ostrom and Simon, 1985; Wittkopf and Dehaven, 1987). In addition to the diversionary theory, we also have some experimental evidence which suggests that competing against a rival group can help improve cooperation among group members in social dilemma games (see, for example, Bornstein et al., 1990; Bornstein and Erev, 1994; Brown, 2000; Erev et al., 1993; Reuben and Tyran, 2010; Tan and Bolle, 2007). But note that none of these experimental studies concerns the effects of group competition on trust restoration for a broken relationship. Group competition may or may not be as effective when facing such a scenario.

\section{HYPOTHESIS 2: Group competition helps restore trust.}

Our third hypothesis relates to the impact of communication via apologetic messages on trust restoration. Since admitting wrongdoings signals responsibility and intention to avoid similar violations in the future, it has been argued by some as one of the most important steps to initiate the process of reconciliation (see, for example, Lewicki and Bunker, 1996). Indeed, numerous studies have found that apologies, especially combined with adequate explanations, are effective in alleviating negative emotions and thus help reconcile two estranged parties (Bies and Shapiro, 1987; Bottom et al., 2002; Schlenker and Darby, 1981; Gibson et al., 1999; Ohbuchi et al., 1989; Ohbuchi and Sato, 1994; Shapiro, 1991). In contrast to these results, Schweitzer et al. (2006) find that apologies carry no significant impact on trust recovery. As the evidence that supports the effectiveness of apologies outweighs the evidence that does not, we conjecture in our paper that apologies, by themselves, are enough to restore trust.

Hypothesis 3: Communication helps restore trust. 
Finally, since no studies, to our best knowledge, have investigated the relative effectiveness of the two trust remedies we consider here, we propose a null hypothesis that communication is as effective as group competition in restoring trust.

Hypothesis 4: Communication is as effective as group competition in restoring trust.

In the next section, we investigate these hypotheses using the data from the four treatments described in Section 2.

\section{Results}

In this section, we first investigate the determinants of the amount stolen by Player B in Section 4.1. We discuss if transgression destroys trust in Section 4.2. The relative effectiveness of trust remedies is reported in Section 4.3.

\subsection{Determinants of the Stealing Behavior}

The distribution of the amounts stolen by Bs in round 3 of the experiment is shown in Fig. 2. When given an opportunity to steal, no one passed up the opportunity and a majority of them actually stole the maximum possible amount of 20 ECUs from Player As. On average, Player Bs stole 15.90 in the Group Competition treatment, 16.75 in the Communication treatment, and 16.33 in the Endogenous Baseline treatment. Pair-wise Mann-Whitney ranksum tests suggest that the amounts stolen in the three treatments are not statistically different.

[Fig. 2: About Here] 
Table 2 reports results from two Tobit models on the amount stolen by Player Bs. The reference group in all these models is the Endogenous Baseline treatment. The explanatory variables included in the first model are a dummy variable which equals 1 for the Group Competition treatment, a second dummy variable which equals 1 for the Communication treatment, and the amount returned by B that is corresponding to A's actual amount sent in round 2. In the second model, we add a gender dummy variable which equals 1 for male and 0 for female, age, years of study, and a dummy variable called "Social Science" that equals 1 if Player B majors in law, economics, management or political science. Consistent with the above finding, the estimated coefficients on the two treatment dummy variables are not statistically significant in either specification. The amount stolen in round 3 is inversely related to the amount returned in round 2, suggesting a positive correlation between one's integrity (honesty) and trustworthiness. The positive estimated coefficient on gender suggests that male trustees tend to steal significantly more than female ones. Finally, the estimated coefficient on age is positive but marginally significant.

[Table 2: About Here]

\subsection{Trust Destruction}

Does the act of stealing undermine Player As' trust towards Player Bs? To answer this question, we need to compare the data from the three treatments where stealing was allowed (Group Competition, Communication, and Endogenous Baseline) with the data from the treatment where income redistributions were done exogenously (Exogenous Baseline). One can get an initial sense of the data by examining amounts sent immediately before (round 2) and after (round 4) stealing took place. The evolution of the average amount sent in the four 
treatments is presented in Fig. 3. The percentage change in the amount sent between rounds 2 and 4 is $-31.29 \%$ in Group Competition, $-33.87 \%$ in Communication, and $-21.41 \%$ in Endogenous Baseline, respectively. In the Exogenous Baseline treatment, the percentage change is merely $-5.22 \%$.

[Fig. 3: About Here]

Table 3 provides further evidence that transgression destroys trust. In Table 3, we report results from two OLS regression models that investigate the effects of redistributions done by the experimenter vs. that by the transgressors. The dependent variable is the percentage change in the amount sent between rounds 2 and 4 . The independent variables are dummy variables representing all possible amounts lost (from Player A's perspective) due to either exogenous, random redistributions or Player Bs' intentional acts of stealing, gender, age, years of study, and the social science dummy variable. In the first model, we employ the data from only the Exogenous Baseline treatment. In the second model, we employ the data from the Group Competition, Communication, and Endogenous Baseline treatments. As a result, we also include two treatment dummy variables in the model. The results are summarized as follows.

[Table 3: About Here]

RESULT 1: An intentional act of stealing that reverses the relative income status between the trustor and the trustee significantly undermines trust. 
SUPPORT FOR RESULT 1: None of the estimated coefficients on lost dummies reported in column (1) of Table 3 is significant, suggesting that exogenous, random redistributions do not affect trust. By contrast, column (2) indicates that an amount lost more than 5 ECUs triggers a significant decrease in the amount sent from round 2 to round 4 , suggesting that an intentional act of stealing that reverses the relative income status could have a devastating effect on A's trust towards B. Furthermore, there is no significant behavioral difference among the three treatments where redistributions were done endogenously.

Note that we interpret the decrease in the amount sent in the Group Competition, Communication, and Endogenous Baseline treatments as deterioration in trust. Yet, we are also mindful of different motivations behind the amount sent in the investment game of Berg et al. ${ }^{10}$ Since there is no evidence in the literature suggesting that transgression such as stealing has a disproportionate impact on other-regarding preferences than on trust, we stand behind our interpretation and consider it as a rough measure of a trust violation.

\subsection{Trust Restoration}

Having learned that transgression undermines trust, we shift our focus to investigate the effectiveness of the two trust remedies that we introduce. We do so by comparing the data from the two treatments where trust remedies were in place with the data from the Endogenous Baseline treatment where no trust remedy was employed.

\footnotetext{
${ }^{10}$ See Cox (2004) for a discussion about different motivations behind the trustor's behavior in the investment game of Berg et al..
} 


\subsubsection{Results from the Group Competition Treatment}

Fig. 3 indicates that, while the average amount sent continues its downward trend and plunges by $7.78 \%$ from round 4 to round 6 in the Endogenous Baseline treatment, it climbs back up from 2.24 to 2.56, a $14.29 \%$ increase in the Group Competition treatment. In Table 4, we report the results from two OLS models that investigate the effectiveness of competition in restoring trust. In the first regression, we consider the Endogenous Baseline treatment as the reference group and include a dummy variable that describes the Group Competition treatment as the explanatory variable. In other words, we do not control for any wealth effects or differentiate between the outcomes of the competition in this regression. In the second regression, we consider those who did not receive extra 20 ECUs in round 5 of the Endogenous Baseline treatment as the reference group. The explanatory variables include a dummy variable that equals 1 if a 20 -ECU reward is received and the interaction of the reward dummy and the Group Competition treatment. Other control variables such as gender, age, years of study, and social science majors are included in both models. The results are summarized in Result 2.

[Table 4: About Here]

RESULT 2: Competing against a rival group helps restore trust.

SUPPORT FOR RESUlt 2: Column (1) of Table 4 indicates that, compared to the Endogenous Baseline treatment, the percentage change in the amount sent between rounds 4 
and 6 is higher, though not significantly, in the Group Competition treatment. Column (2) suggests that, after the monetary reward and its interaction with the treatment variable are controlled for, group competition yields a significant increase in the percentage change in the amount sent. The monetary reward, by itself or interacting with the competition treatment, has no significant impact on the percentage change in the amount sent. ${ }^{11}$

\subsubsection{Results from the Communication Treatment}

Before analyzing the effectiveness of communication, let us first investigate the messages choices made by Player Bs. We find that $35 \%$ of Player Bs chose to send a message to apologize, whereas $25 \%$ of them sent a message that denied any wrongdoing. As a result, $40 \%$ of Player Bs decided to opt out from communication. The average amounts stolen by Player Bs who chose these respective options are 17.50, 16.00, and 16.56, respectively. Pairwise Mann-Whitney rank-sum tests suggest that the differences between the amounts stolen are not statistically significant. At the individual level, the correlation between the amount stolen and the choice of communication (assigning 1 to apology, 2 to no apology, and 3 to no message sent) is -0.08 , which is not significant at any conventional level.

As for the effectiveness of communication, Fig. 3 shows that the average amount sent decreases by about $7.32 \%$ from round 4 to round 6 . Compared to a $7.78 \%$ decline in the Endogenous Baseline treatment, communication via a preprogrammed message does not seem to have a significant impact on restoring trust. But again, to investigate the effect more

\footnotetext{
${ }^{11}$ The estimated coefficient on Competition $\times$ Reward, though statistically insignificant, suggests that winning could slightly undermine the restorative effect of competition. Perhaps it was because having a 20-ECU monetary prize on hand makes entrusting one's own endowment a less urgent need in the investment/trust game. It could also be related to the notion that negative shocks or natural disasters increase solidarity (see, for example, Drabek (1986), Carretero and Angel (2003), Collins (2004), Harlow and Dundes (2004), Smelser (2004), and Hawdon et al. (2010)).
} 
rigorously, we need to adopt a regression analysis to control for wealth effects and the impact of various message choices. In the first regression reported in Table 5, we simply include a dummy variable that equals 1 for the Communication treatment and 0 for the Endogenous Baseline. In the second regression, we consider those who did not receive extra 20 ECUs in round 5 of the Endogenous Baseline treatment as the reference group. We include the reward dummy as described above to control for wealth effects and three dummy variables to reflect the message choices in the Communication treatment. Other control variables included in previous regression models are also taken into consideration here. We summarize the results in Result 3.

[Table 5: About Here]

RESULT 3: Communication via a preprogrammed message has no significant impact on trust restoration.

SUPPORT FOR RESULT 3: Column (1) of Table 5 shows that the percentage change in the amount sent between rounds 4 and 6 in the Communication treatment is not significantly different from that in the Endogenous Baseline treatment. After we differentiate among the three message choices and also control for wealth effects, we find that, compared to the reference group in the Endogenous Baseline treatment, sending a pre-programmed message, apologetic or not, does not significantly influence the amount sent from rounds 4 to 6 . This result suggests that communication via an impersonal message is not an effective tool to restore trust. 


\section{Robustness Check of the Communication Effect}

One explanation for the different effectiveness of the two trust remedies is that an impersonal apology tends to limit the scope of its influence. Schlenker and Darby (1981) identify several apologetic components ranging from a more perfunctory statement such as "I am sorry" to an expression of remorse, an offer of restitution, a self-castigation, an attempt for forgiveness, an explanation for transgression, and a promise for future behavior. The lack of sincere components might have made our pre-programmed message rather disingenuous. The second explanation concerns the form of communication. Ben-Ner et al. (2011), Buchan et al. (2006), Charness and Dufwenberg (2006, 2007), and Cooper and Kuhn (2012) all find that personal communication, strategy relevant or not, has a more significant impact than impersonal communication on trust or cooperation, suggesting that the relatively weak effect found in our Communication treatment could be partially due to the form we chose. ${ }^{12}$

To check the robustness of the communication effect, we designed a new treatment, called the Free-Form Communication treatment, in which the pre-programmed message was replaced by free-form communication. Specifically, in round 5 of the Free-Form Communication treatment, a private chat window was opened for two minutes for players to send text messages to their paired counterparts. Subjects were not allowed to reveal their identities or to discuss their decisions made in rounds 2 and 4 (trust games). Other than these restrictions, they were not constrained by what they could write in their messages. We conducted two sessions (48 participants) in which only player Bs were allowed to send text messages and two sessions (48 participants) in which both As and Bs were allowed to do so.

\footnotetext{
${ }^{12}$ Besedes et al. (2012), Isaac et al. (1985), Isaac and Walker (1991), and Krishnamurthy (2001) also find freeform communication helps enhance cooperation in the context of VCM games.
} 
This allows us to check whether two-way communication has a stronger restorative impact than one-way communication. Summary information about each of these four sessions is also given in Table 1. Including the show-up fee, subjects earned an average of 15.66 Euros.

The evolution of the average amount sent in the Free-Form Communication treatment is also shown in Fig. 3. The general pattern appears to be very similar to that in the Group Competition treatment shown in the same figure.

To see if transgression destroys trust, we run an OLS regression similar to that in Table 3 to investigate the effects of redistributions done by the transgressors. In addition to the dummy variables representing all possible amounts stolen by Player B, gender, age, years of study, and the social science dummy variable, we also include a dummy variable that equals 1 for two-way free-form communication and 0 otherwise. The estimated coefficients reported in Table 6 indicate that only severe transgression that makes Player As lose 20 ECUs has a significant impact on the amount sent in the Free-Form Communication treatment.

[Table 6: About Here]

Is free-form communication effective in restoring trust? Fig. 3 shows that, contrary to the persistent downward trend in the Endogenous Baseline treatment, the amount sent in round 6 of the Free-Form Communication treatment increases by $10.20 \%$ from round 4 , suggesting that free-form communication helps improve trust. A regression analysis is conducted to verify the impact of free-form communication. Similar to the first regression model in Table 5, we first include only dummy variables that indicate if the free-form communication is one-way or two-way. Since the results reported in column (1) of Table 7 indicate that there is no significant difference between one-way and two-way communication, we combine the data from both in the second regression model and simply include three 
dummy variables (Personalized Apology, Explanation, and Other Messages) reflecting if certain contents were found in the messages and a dummy variable that equals 1 if no action was taken. A dummy variable that describes the monetary reward given to half of the pairs in the Endogenous Baseline treatment is also included in the second regression model in order to control for wealth effects. Finally, in the third regression, we adopt a more comprehensive approach by employing the data from all treatments except the Exogenous Baseline to investigate the relative effectiveness of all trust remedies. We summarize the results in Result 4.

[Table 7: About Here]

RESULT 4: Communication via a personalized apology has a positive but insignificant impact on mending a broken relationship. Explanations for the transgression, on the other hand, are as effective as competing against a rival group in restoring trust.

SUPPORT FOR RESULT 4: The estimated coefficients reported in column (1) of Table 7 indicate that, compared to the Endogenous Baseline treatment, the average amount sent with either one-way or two-way free-form communication increases. Neither coefficient is statistically significant. After wealth effects and the contents included in the messages are controlled for, column (2) of Table 7 shows that sending personalized apologies has no significant effect on the percentage change in the amount sent. Explanations for misbehavior, on the other hand, help increase the amount sent significantly from rounds 4 to 6 . Finally, after all four treatments (Endogenous Baseline, Competition, Communication, and Free-Form Communication) are taken into consideration, the estimated coefficients on explanations and 
group competition as shown in column (3) remain positive and significant. The hypothesis that explanations and group competition have the same impact cannot be rejected at any conventional level $(p$-value $=0.5872)$.

\section{Conclusion}

Trust is essential. Without trust, a relationship cannot flourish or survive. Trust is also fragile. It needs to be cultivated with great effort and maintained with immense care. In this study, we investigate the fragility aspect of trust. We ask whether trust can be easily destroyed and if and how it can be restored. We find that transgression outside a direct exchange relationship can have a devastating effect on trust. But contrary to the notion that trust is hard to restore, we find that a remedy that reconsolidates the group-competing against a rivalry group in our case-helps reestablish it. Communication via an apology, personal or impersonal, has no significant impact on mending a broken relationship. Having said that, we do find that offering explanations for misbehavior is as effective as group competition to restore trust.

Our result that trust can be effectively restored, though consistent with the finding in Schweitzer et al. (2006), should not be taken as a complete rejection of the common notion that trust is vulnerable. After all, stealing 20 ECUs in the lab may not be as serious as some of the trust violations in the naturally occurring world. Instead, we think it is more useful to emphasize the experimental results as insights into the relative effectiveness of different trust remedies. From this perspective, our results highlight the significance of a potential threat from a rival group as well as the form and the contents of communication when used to 
rebuild a broken relationship. Future work could examine the robustness of these effective tools and, more importantly, the channels through which trust is affected or restored. 


\section{References}

Ben-Ner, A., Putterman, L., 2009. Trust, communication and contracts: an experiment. Journal of Economic Behavior and Organization 70(1-2), 106-121.

Ben-Ner, A., Putterman, L., Ren, T., 2011. Lavish returns on cheap talk: two-way communication in trust games. Journal of Socio-Economics 40(1), 1-13.

Berg, J., Dickhaut, J., McCabe, K., 1995. Trust, reciprocity, and social history. Games and Economic Behavior 10, 122-142.

Besedes T., Deck, C., Quintanar, S., Sarangi S., Shor, M., 2012. Free-riding and performance in collaborative and non-collaborative groups. MPRA Paper No. 33948.

Bies, R.J., Shapiro, D.L., 1987. Interactional fairness judgments: the influence of causal accounts. Social Justice Research 1, 199-218.

Blanning, T.C.W, 1986. The origins of the French Revolutionary Wars. London: Longmans.

Bohnet, I., Harmgart, H., Huck, S., and Tyran, J-R., 2005. Learning trust. Journal of European Association 3(2-3), 322-329.

Bolton, G., E. Katok, and A. Ockenfels, 2004. How effective are electronic reputation mechanisms? An experimental investigation. Management Science 50(11), 1587-1602.

Bolton, G., Katok, E., Ockenfels, A., 2005. Cooperation among strangers with limited information about reputation. Journal of Public Economics 89, 1457-1468.

Bornstein, G., Erev, I., Rosen, O., 1990. Intergroup competition as a structural solution to social dilemmas. Social Behavior 5, 247-260.

Bornstein, G., Erev, I., 1994. The enhancing effect of intergroup competition on group performance. International Journal of Conflict Management 5, 271-281.

Bottom, W. P., Gibson, K., Daniels, S.E., Murnighan, J.K., 2002. When talk is not cheap: substantive penance and expressions of intent in rebuilding cooperation. Organization Science 13(5), 497-513.

Brown, R., 2000. Group Processes, Blackwell, Oxford.

Brown, M. and C. Zehnder, 2007. Credit Reporting, Relationship Banking and Loan Repayment. Journal of Money, Credit, and Banking 39(8), 1883-1918.

Buchan, N., Croson, R., Johnson, E., 2006. Let's get personal: an international examination of the influence of communication, culture and social distance on other regarding preferences. Journal of Economic Behavior and Organization 60, 373-398.

Burk, S., Carpenter, J., Verhoogen, E., 2003. Playing both roles in the trust game. Journal of Economic Behavior and Organization 51(2), 195-216. 
Butler, J.K., Jr. 1991. Toward understanding and measuring conditions of trust. Journal of Management 17(3), 643-663.

Butler, J.K., Jr., Cantrell, R.S., 1984. A behavioral decision theory approach to modeling dyadic trust in superiors and subordinates. Psychological Reports 55, 19-28.

Carretero, P., Angel, E., 2003. Social reaction in the face of catastrophe: an interpretation of communal response to an ecological crisis. Societies 3, 91-103.

Charness, G., Dufwenberg, M., 2006. Promises and partnerships. Econometrica 74(6), 15791601.

Charness G., Dufwenberg, M., 2007. Broken promises: an experiment. Working Paper.

Charness, G., Du., N., Du, Yang, C-L., 2011. Trust and trustworthiness reputation in an investment game. Games and Economic Behavior 72(2), 361-375.

Charness, G., Masclet, D., Villeval, M.C., 2013. Competitive preferences and status as an incentive: experimental evidence. Management Science, forthcoming.

Chaudhuri A., Gangadharan, L., 2003. Gender differences in trust games and reciprocity. Working Paper.

Croson, R., Buchan, N., 1999. Gender and culture: international experimental evidence from trust games. American Economic Review Papers and Proceedings 89(2), 386-91.

Collins, R., 2004. Rituals of solidarity and security in the wake of terrorist attack.

Sociological Theory 22, 53-87.

Cooper, D.J., Kuhn, K-U., 2012. Communication, renegotiation, and the scope for collusion. Working Paper.

Coser, L.A., 1956. The Functions of Social Conflict. New York: Free Press.

Cox, J.C., 2004. How to identify trust and teciprocity. Games and Economic Behavior 46, 260-281.

Drabek, T.E., 1986. Human System Responses to Disaster. New York: Springer-Verlag.

Duffy, J., Xie, H., Lee, Y-J., 2013. Social norms, information and trust among strangers: theory and evidence. Economic Theory 52(2), 669-708.

Dunn, J., Schweitzer, M., 2005. Feeling and believing: the influence of emotion on trust. Journal of Personality and Social Psychology 88, 736-748.

Erev, I., Bornstein, G., Galili, R., 1993. Constructive intergroup competition as a solution to the free rider problem: a field experiment. Journal of Experimental Social Psychology 29, 463-478. 
Fischbacher, U., 2007. z-Tree: Zurich Toolbox for Ready-Made Economic Experiments. Experimental Economics, 10(2), 171-178.

Gabarro, J.J., 1978. The Development of Trust, Influence, and Expectations. in Interpersonal Behaviors: Communication and Understanding in Relationships, A. G. Athos and J. J. Gabarro eds., Englewood Cliffs, NJ: Prentice Hall.

Gibson, K., Bottom, W., Murnighan, K., 1999. Once bitten: defection and reconciliation in a cooperative enterprise. Business Ethics Quarterly 9, 69-85.

Glaeser, E., Laibson, D., Scheinkman, J., Soutter, C., 2000. Measuring trust. Quarterly Journal of Economics 65, 811-846.

Greiner, B., 2004. The Online Recruitment System ORSEE 2.0 - A guide for the organization of experiments in economics. Working Paper Series in Economics 10, University of Cologne, Department of Economics.

Harlow, R., Dundes, L., 2004. 'United' we stand: responses to the September 11 attacks in black and white. Sociological Perspectives 47, 439-464.

Isaac, R.M., Walker, J., 1991. Costly Communication: An Experiment in a Nested Public Goods Problem. In T. Palfrey (Ed.), Laboratory Research in Political Economy. Ann Harbor: University of Michigan Press.

Isaac, R.M., McCue, K., Plott, C.R., 1985. Public good provision in an experimental environment. Journal of Public Economics 26, 51-74

Jones, J.M., 2013, September 26. Americans' trust in government generally down this year. Retrieved from http://www.gallup.com/poll/164663/americans-trust-government-generallydown-year.aspx.

Kernell, S., 1978. Explaining presidential popularity. American Political Science Review 72, 506-522.

Keser, C., 2003. Experimental games for the design of reputation management systems. IBM Systems Journal 42(3), 498-506.

Krishnamurthy, R., 2001. Communication effects in public good games with and without provision points. Research in Experimental Economics 8, 25-42.

Langer, W.L., 1969. The origin of the Russo-Japanese war. In C. Schorske and E. Schorske (Eds.), Explorations in Crisis: Papers on International History by William Langer. Cambridge, MA: Harvard University/Belknap Press.

Lebow, R.N., 1981. Between Peace and War: The Nature of International Crisis. Baltimore: Johns Hopkins University Press.

Lee, J.R., 1977. Rallying 'round the flag. Presidential Studies Quarterly 7, 252-256. 
Lewicki, R.J., Bunker, B.B., 1996. Developing and maintaining trust in work relationships. In R. M. Kramer and T. R. Tyler (Eds.), Trust in Organizations: Frontiers of Theory and Research. Thousand Oaks, CA: Sage, 114-139.

Lewicki, R.J., Tomlinson, E.C., Gillespie, N., 2006. Models of interpersonal trust development: theoretical approaches, empirical evidence, and future directions. Journal of Management 32, 991-1021.

MacKuen, M., 1983. Political drama, economic conditions, and the dynamics of presidential popularity. American Journal of Political Science 27, 165-192.

Malhotra, D., Murnighan, J.K., 2002. The effects of contracts on interpersonal trust. Administrative Science Quarterly 47(3), 534-559.

Manchin, A., 2013, October 30. Trust in government sinks to new low in southern Europe.

Retrieved from http://www.gallup.com/poll/165647/trust-government-sinks-new-low-

southern-europe.aspx.

Mueller, J.E., 1973. War, Presidents, and Public Opinion. New York: Wiley.

Ohbuchi, K., Kameda, M., Agarie, N., 1989. Apology as aggression control: its role in mediating appraisal of and response to harm. Journal of Personality and Social Psychology $56,219-227$.

Ohbuchi, K., Sato, K., 1994. Children's reactions to mitigating accounts: apologies, excuses, and intentionality of harm. The Journal of Social Psychology 134, 5-17.

Ortmann, A., Hertwig, R., 2002. The costs of deception: evidence from psychology. Experimental Economics 5, 111-131.

Ostrom, C.W., Simon, D., 1985. Promise and performance: a dynamic model of presidential popularity. American Political Science Review 79, 334-358.

Reuben, E., Tyran, J-R., 2010. Everyone is a winner: promoting cooperation through all-canwin intergroup competition. European Journal of Political Economy 26, 25-35.

Schlenker, B.R., Darby, B.W., 1981. The use of apologies in social predicaments. Social Psychology Quarterly 44, 271-278.

Schweitzer, M., Hershey, J., Bradlow, E., 2006. Promises and lies: restoring violated trust. Organizational Behavior and Human Decision Processes 101(1), 1-19.

Servatka, M., Tucker, S., Vadovic, R., 2011. Words speak louder than money. Journal of Economic Psychology 32(5), 700-709.

Shapiro, D., 1991. The effects of explanations on negative reactions to deceit. Administrative Science Quarterly 4, 614-630. 
Simmel, G., 1956. Conflict and the Web of Group Affiliation. Glencoe, IL: Free Press.

Smelser, N.J., 2004. Collective Trauma and Collective Identity. Berkeley: University of California Press.

Tan, J., Bolle, F., 2007. Team competition and the public goods game. Economics Letters 96, 133-139.

White, J.A., 1964. The Diplomacy of the Russo-Japanese War. Princeton, N.J.: Princeton University Press.

Willinger M., Keser, C., Lohmann, C., Usunier, J.C., 2003. A comparison of trust and reciprocity between France and Germany: experimental investigation based on the investment game. Journal of Economic Psychology 24(4), 447-466.

Wittkopf, E.R., Dehaven, M.J., 1987. Soviet behavior, presidential popularity, and the penetration of open political systems. In C. F. Hermann, C.W. Kegley, Jr., and J.N. Rosenau (Eds.), New Directions in the Study of Foreign Policy. Boston: Unwin Hyman. 
Table 1.

Summary of the experimental sessions.

\begin{tabular}{|c|c|c|c|c|c|c|c|c|}
\hline Treatment & $\begin{array}{l}\text { Session } \\
\text { Number }\end{array}$ & $\begin{array}{c}\text { Number } \\
\text { of } \\
\text { Subjects }\end{array}$ & $\begin{array}{l}\text { Round } \\
1\end{array}$ & $\begin{array}{c}\text { Round } \\
2\end{array}$ & $\begin{array}{c}\text { Round } \\
3\end{array}$ & $\begin{array}{c}\text { Round } \\
4\end{array}$ & $\begin{array}{c}\text { Round } \\
5\end{array}$ & $\begin{array}{c}\text { Round } \\
6\end{array}$ \\
\hline \multirow{3}{*}{$\begin{array}{l}\text { Exogenous } \\
\text { Baseline }\end{array}$} & 1 & 20 & \multirow{19}{*}{$\begin{array}{l}\text { Decoding } \\
\text { Task }\end{array}$} & \multirow{19}{*}{$\begin{array}{l}\text { Trust } \\
\text { Game }\end{array}$} & \multirow{3}{*}{$\begin{array}{l}\text { Exog. } \\
\text { Income } \\
\text { Redistri. }\end{array}$} & \multirow{19}{*}{$\begin{array}{l}\text { Trust } \\
\text { Game }\end{array}$} & \multirow{11}{*}{$\begin{array}{c}\text { Group } \\
\text { Competition }\end{array}$} & \multirow{19}{*}{$\begin{array}{l}\text { Trust } \\
\text { Game }\end{array}$} \\
\hline & 2 & 20 & & & & & & \\
\hline & 3 & 20 & & & & & & \\
\hline \multirow{3}{*}{$\begin{array}{l}\text { Endogenous } \\
\text { Baseline }\end{array}$} & 4 & 20 & & & \multirow{16}{*}{$\begin{array}{l}\text { Income } \\
\text { Redistri. } \\
\text { by B }\end{array}$} & & & \\
\hline & 5 & 20 & & & & & & \\
\hline & 6 & 20 & & & & & & \\
\hline \multirow{5}{*}{$\begin{array}{c}\text { Group } \\
\text { Competition }\end{array}$} & 7 & 20 & & & & & & \\
\hline & 8 & 20 & & & & & & \\
\hline & 9 & 20 & & & & & & \\
\hline & 10 & 24 & & & & & & \\
\hline & 11 & 16 & & & & & & \\
\hline \multirow{4}{*}{ Communication } & 12 & 16 & & & & & \multirow{4}{*}{$\begin{array}{l}\text { Pre- } \\
\text { programmed } \\
\text { Message }\end{array}$} & \\
\hline & 13 & 20 & & & & & & \\
\hline & 14 & 20 & & & & & & \\
\hline & 15 & 24 & & & & & & \\
\hline \multirow{4}{*}{$\begin{array}{c}\text { Free-Form } \\
\text { Communication }\end{array}$} & $16^{\mathrm{a}}$ & 24 & & & & & \multirow{4}{*}{ Free Chat } & \\
\hline & $17^{\mathrm{a}}$ & 24 & & & & & & \\
\hline & $18^{\mathrm{b}}$ & 24 & & & & & & \\
\hline & $19^{\mathrm{b}}$ & 24 & & & & & & \\
\hline
\end{tabular}

Notes: ${ }^{a}$ : Free-Form one-way communication. ${ }^{b}$ : Free-Form two-way communication. 
Table 2.

Determinants of the amount stolen by player B from Tobit models.

(Data from Endogenous Baseline, Group Competition, and Communication treatments)

\begin{tabular}{lcc}
\hline \hline Dependent Variable: & $(1)$ & $(2)$ \\
Amount Stolen & $29.264^{* * *}$ & $-8.091^{* * *}$ \\
\hline Constant & $(3.024)$ & $(18.875)$ \\
& -2.487 & -2.489 \\
Competition & $(2.716)$ & $(2.689)$ \\
& -1.739 & -1.437 \\
Communication & $(2.885)$ & $(2.808)$ \\
& $-1.548^{* * *}$ & $-1.469^{* * *}$ \\
Amount Returned in Round 2 & $(0.339)$ & $(0.327)$ \\
& & $5.249^{* *}$ \\
Male & & $(2.174)$ \\
& & $1.700^{*}$ \\
Age & & $(0.986)$ \\
& & -0.275 \\
Years of Study & & $(1.553)$ \\
& & 2.111 \\
Social Sciences & & $(3.060)$ \\
\hline Observations & 120 & 120 \\
Left cens. & 0 & 0 \\
Right cens. & 73 & 73 \\
Loglikelihood & -213.02 & -208.04 \\
\hline \hline
\end{tabular}

Notes: $* * *, * *$ and $*$ : Significant at the $1 \%, 5 \%$, and $10 \%$ level, respectively. Standard errors are in parentheses. 
Table 3.

Percentage change in the amount sent between rounds 2 and 4 from OLS models.

\begin{tabular}{|c|c|c|}
\hline $\begin{array}{l}\text { Dependent Variable: } \\
\left(\text { sent }_{4}-\text { sent }_{2}\right) / \text { sent }_{2}\end{array}$ & $\begin{array}{c}(1) \\
\text { Exog. Baseline }\end{array}$ & $\begin{array}{c}(2) \\
\text { Endog. Baseline } \\
+ \\
\text { Competition } \\
+ \\
\text { Communication } \\
\end{array}$ \\
\hline Constant & $\begin{array}{l}-1.852 \\
(5.332)\end{array}$ & $\begin{array}{l}3.562^{*} \\
(2.004)\end{array}$ \\
\hline Lost5 & Ref. & Ref. \\
\hline Lost10 & $\begin{array}{l}1.014 \\
(2.053)\end{array}$ & $\begin{array}{c}-1.242 * * * \\
(0.469)\end{array}$ \\
\hline Lost15 & $\begin{array}{l}1.113 \\
(1.294)\end{array}$ & $\begin{array}{c}-1.153 * * \\
(0.483)\end{array}$ \\
\hline Lost20 & $\begin{array}{c}0.473 \\
(1.104)\end{array}$ & $\begin{array}{c}-1.357 * * * \\
(0.402)\end{array}$ \\
\hline Competition & & $\begin{array}{c}0.243 \\
(0.281)\end{array}$ \\
\hline Communication & & $\begin{array}{l}0.110 \\
(0.294)\end{array}$ \\
\hline Male & $\begin{array}{l}-0.612 \\
(0.748)\end{array}$ & $\begin{array}{l}-0.202 \\
(0.236)\end{array}$ \\
\hline Age & $\begin{array}{c}0.042 \\
(0.317)\end{array}$ & $\begin{array}{l}-0.135 \\
(0.108)\end{array}$ \\
\hline Years of Study & $\begin{array}{c}0.241 \\
(0.474)\end{array}$ & $\begin{array}{l}-0.008 \\
(0.173)\end{array}$ \\
\hline Social Sciences & $\begin{array}{c}0.521 \\
(0.992)\end{array}$ & $\begin{array}{c}0.090 \\
(0.307)\end{array}$ \\
\hline $\mathrm{R}^{2}$ & 0.090 & 0.137 \\
\hline Adjusted $\mathrm{R}^{2}$ & -0.199 & 0.065 \\
\hline Observations & 30 & 117 \\
\hline
\end{tabular}

Notes: ${ }^{\text {a: }}$ Adjusted $\mathrm{R}^{2}$ can be negative when the model contains many independent variables that do not help explain the data. $* * *, * *$ and $*$ : Significant at the $1 \%, 5 \%$, and $10 \%$ level, respectively. Standard errors are in parentheses. 
Table 4.

Percentage change in the amount sent between rounds 4 and 6 from OLS models. (Data from Endogenous Baseline and Group Competition treatments)

\begin{tabular}{lcc}
\hline \hline $\begin{array}{l}\text { Dependent Variable: } \\
\left(\text { sent }_{6}-\text { sent }_{4}\right) / \text { sent }_{4}\end{array}$ & $(1)^{\mathrm{a}}$ & $(2)^{\mathrm{b}}$ \\
\hline Constant & -1.735 & -2.703 \\
& $(3.500)$ & $(3.446)$ \\
Competition & 0.531 & $1.066^{* *}$ \\
& $(0.352)$ & $(0.467)$ \\
Reward & & 0.068 \\
& & $(0.517)$ \\
Competition $\times$ Reward & & -1.032 \\
& -0.536 & $(0.657)$ \\
Male & $(0.377)$ & -0.527 \\
& 0.133 & $(0.364)$ \\
Age & $(0.202)$ & 0.185 \\
& -0.424 & $(0.197)$ \\
Years of Study & $(0.328)$ & $-0.548^{*}$ \\
& -0.195 & $(0.321)$ \\
Social Sciences & $(0.386)$ & -0.002 \\
& 0.114 & $0.386)$ \\
\hline $\mathrm{R}^{2}$ & -0.006 & 0.228 \\
Adjusted $\mathrm{R}^{2}$ & 43 & 0.073 \\
Observations & & 43 \\
\hline \hline
\end{tabular}

Notes: ${ }^{\text {a }}$ : The reference group is the Endogenous Baseline treatment. ${ }^{\text {b: }}$ The reference group is the group of players who did not receive extra 20 ECUs in round 5 of the Endogenous Baseline treatment. ** and *: Significant at the 5\% and 10\% level, respectively. Standard errors are in parentheses. 
Table 5.

Percentage change in the amount sent between rounds 4 and 6 from OLS models. (Data from Endogenous Baseline and Communication treatments)

\begin{tabular}{lcc}
\hline \hline $\begin{array}{l}\text { Dependent Variable: } \\
\left(\text { sent }_{6}-\text { sent }_{4}\right) / \text { sent }_{4}\end{array}$ & $(1)^{\mathrm{a}}$ & $(2)^{\mathrm{b}}$ \\
\hline Constant & 0.350 & 0.932 \\
& $(2.778)$ & $(2.801)$ \\
Communication & 0.124 & \\
& $(0.326)$ & \\
Reward & & 0.079 \\
& & $(0.431)$ \\
Apology & & -0.098 \\
& & $(0.515)$ \\
No Apology & & -0.165 \\
& & $(0.481)$ \\
No Message Sent & & 0.612 \\
& -0.404 & $(0.458)$ \\
Male & $(0.307)$ & -0.445 \\
& -0.023 & $(0.310)$ \\
Age & $(0.142)$ & -0.045 \\
& 0.059 & $-0.142)$ \\
Years of Study & $(0.229)$ & $(0.229)$ \\
& -0.105 & -0.173 \\
Social Sciences & $(0.525)$ & $(0.536)$ \\
\hline $\mathrm{R}^{2}$ & 0.058 & 0.175 \\
Adjusted ${ }^{2}$ & -0.085 & -0.045 \\
Observations & 39 & 39 \\
\hline \hline
\end{tabular}

Notes: ${ }^{\text {a }}$ : The reference group is the Endogenous Baseline treatment. ${ }^{\mathrm{b}}$ : The reference group is the group of players who did not receive extra 20 ECUs in round 5 of the Endogenous Baseline treatment. 
Table 6.

Percentage change in the amount sent between rounds 2 and 4 from OLS models. (Data from the Free-Form Communication treatment)

\begin{tabular}{lc}
\hline \hline $\begin{array}{l}\text { Dependent Variable: } \\
\left(\text { sent }_{4}-\text { sent }_{2}\right) / \text { sent }_{2}\end{array}$ & \\
\hline Constant & -1.101 \\
& $(2.121)$ \\
Lost0/Lost5 & Ref. \\
Lost10 & 0.311 \\
& $(0.580)$ \\
Lost15 & -0.381 \\
& $(0.582)$ \\
Lost20 & $-1.038^{* *}$ \\
& $(0.491)$ \\
Two-way & 0.020 \\
& $(0.305)$ \\
Male & -0.103 \\
& $(0.333)$ \\
Age & 0.092 \\
& $(0.117)$ \\
Years of Study & 0.007 \\
& $(0.203)$ \\
Social Sciences & 0.014 \\
& $(0.365)$ \\
\hline $\mathrm{R}^{2}$ & 0.325 \\
Adjusted R & 0.179 \\
Observations & 46 \\
\hline \hline
\end{tabular}

Notes: **: Significant at the $5 \%$ level. Standard errors are in parentheses. 
Table 7.

Percentage change in the amount sent between rounds 4 and 6 from OLS models.

\begin{tabular}{|c|c|c|c|}
\hline $\begin{array}{l}\text { Dependent Variable: } \\
\left(\text { sent }_{6}-\text { sent }_{4}\right) / \text { sent }_{4}\end{array}$ & $\begin{array}{c}(1)^{\mathrm{a}} \\
\text { Endog. Baseline } \\
+ \\
\text { Free-Form } \\
\text { Communication }\end{array}$ & $\begin{array}{c}(2)^{0} \\
\text { Endog. Baseline } \\
+ \\
\text { Free-Form } \\
\text { Communication }\end{array}$ & $\begin{array}{c}(3)^{0} \\
\text { Endog. Baseline } \\
+ \\
\text { Competition } \\
+ \\
\text { Communication } \\
+ \\
\text { Free-Form } \\
\text { Communication } \\
\end{array}$ \\
\hline Constant & $\begin{array}{c}0.779 \\
(0.963)\end{array}$ & $\begin{array}{c}0.120 \\
(0.972)\end{array}$ & $\begin{array}{c}0.628 \\
(1.074)\end{array}$ \\
\hline $\begin{array}{l}\text { Free-Form One-Way } \\
\text { Free-Form Two-way }\end{array}$ & $\begin{array}{c}0.195 \\
(0.254) \\
0.191 \\
(0.266)\end{array}$ & & \\
\hline Personalized Apology & & $\begin{array}{c}0.674 \\
(0.459)\end{array}$ & $\begin{array}{c}0.794 \\
(0.597)\end{array}$ \\
\hline Explanation & & $\begin{array}{c}1.296^{* * *} * \\
(0.466)\end{array}$ & $\begin{array}{c}1.191 * * \\
(0.603)\end{array}$ \\
\hline Other Messages & & $\begin{array}{l}-0.202 \\
(0.312)\end{array}$ & $\begin{array}{l}-0.235 \\
(0.404)\end{array}$ \\
\hline No Action Taken & & $\begin{array}{l}0.360 \\
(0293)\end{array}$ & $\begin{array}{c}0.333 \\
(0.381)\end{array}$ \\
\hline Competition & & & $\begin{array}{l}0.875^{* *} \\
(0.407)\end{array}$ \\
\hline Reward & & $\begin{array}{c}0.0001 \\
(0.350)\end{array}$ & $\begin{array}{l}-0.094 \\
(0.448)\end{array}$ \\
\hline Competition $\times$ Reward & & & \\
\hline Impersonal Apology & & & $\begin{array}{l}-0.223 \\
(0.508)\end{array}$ \\
\hline No Apology & & & $\begin{array}{l}-0.538 \\
(0.446)\end{array}$ \\
\hline No Message $\mathrm{S}$ & & & $\begin{array}{c}0.247 \\
(0.435)\end{array}$ \\
\hline Male & $\begin{array}{c}-0.416^{*} \\
(0.235)\end{array}$ & $\begin{array}{c}-0.417 * \\
(0.219)\end{array}$ & $\begin{array}{l}-0.070 \\
(0.203)\end{array}$ \\
\hline Age & $\begin{array}{l}-0.017 \\
(0.053)\end{array}$ & $\begin{array}{c}0.008 \\
(0.052)\end{array}$ & $\begin{array}{l}-0.033 \\
(0.057)\end{array}$ \\
\hline Years of Study & $\begin{array}{c}-0.314 * * \\
(0.131)\end{array}$ & $\begin{array}{c}-0.285^{* *} \\
(0.125)\end{array}$ & $\begin{array}{l}-0.122 \\
(0.126)\end{array}$ \\
\hline Social Sciences & $\begin{array}{c}0.158 \\
(0.242)\end{array}$ & $\begin{array}{c}0.309 \\
(0.229)\end{array}$ & $\begin{array}{c}0.201 \\
(0.241)\end{array}$ \\
\hline $\mathrm{R}^{2}$ & 0.259 & 0.431 & 0.259 \\
\hline Adjusted $\mathrm{R}^{2}$ & 0.157 & 0.306 & 0.135 \\
\hline Observations & 51 & 51 & 99 \\
\hline
\end{tabular}

Notes: ${ }^{a}$ : The reference group is the Endogenous Baseline treatment. ${ }^{\text {b: }}$ The reference group is the group of players who did not receive extra 20 ECUs in round 5 of the Endogenous Baseline treatment. ***,** and *: Significant at the $1 \%, 5 \%$, and $10 \%$ level, respectively. Standard errors are in parentheses. 


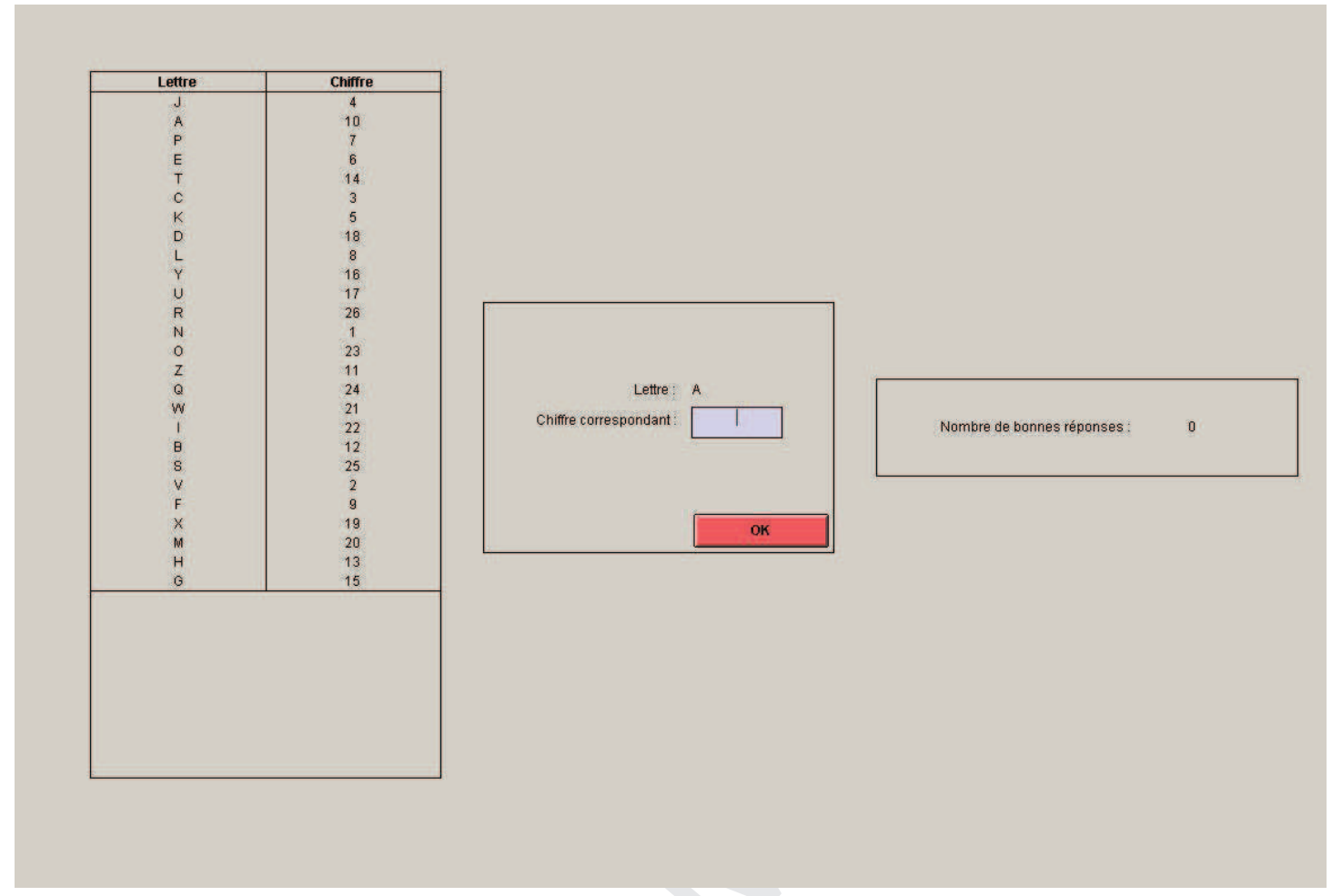

Fig. 1. Screenshot of the decoding task. 


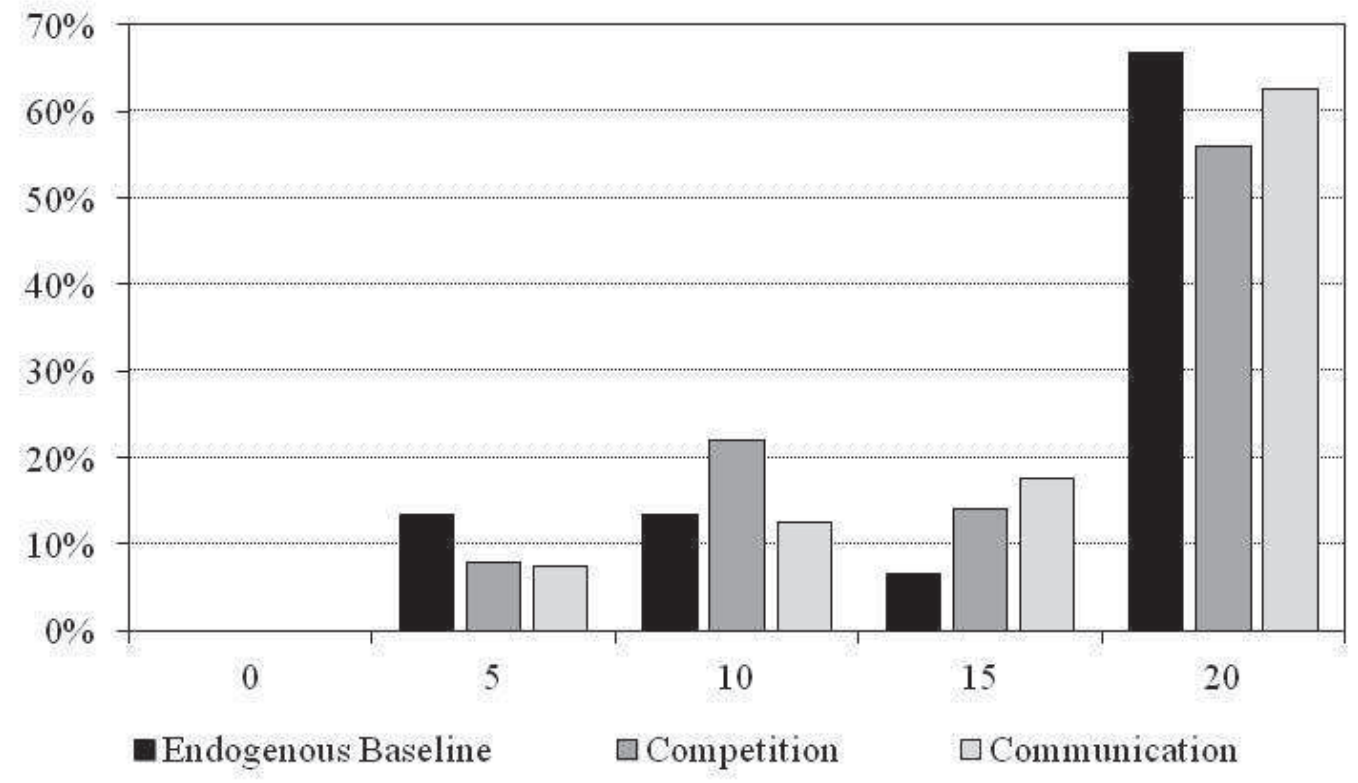

Fig. 2. The distribution of amounts stolen by player Bs. 


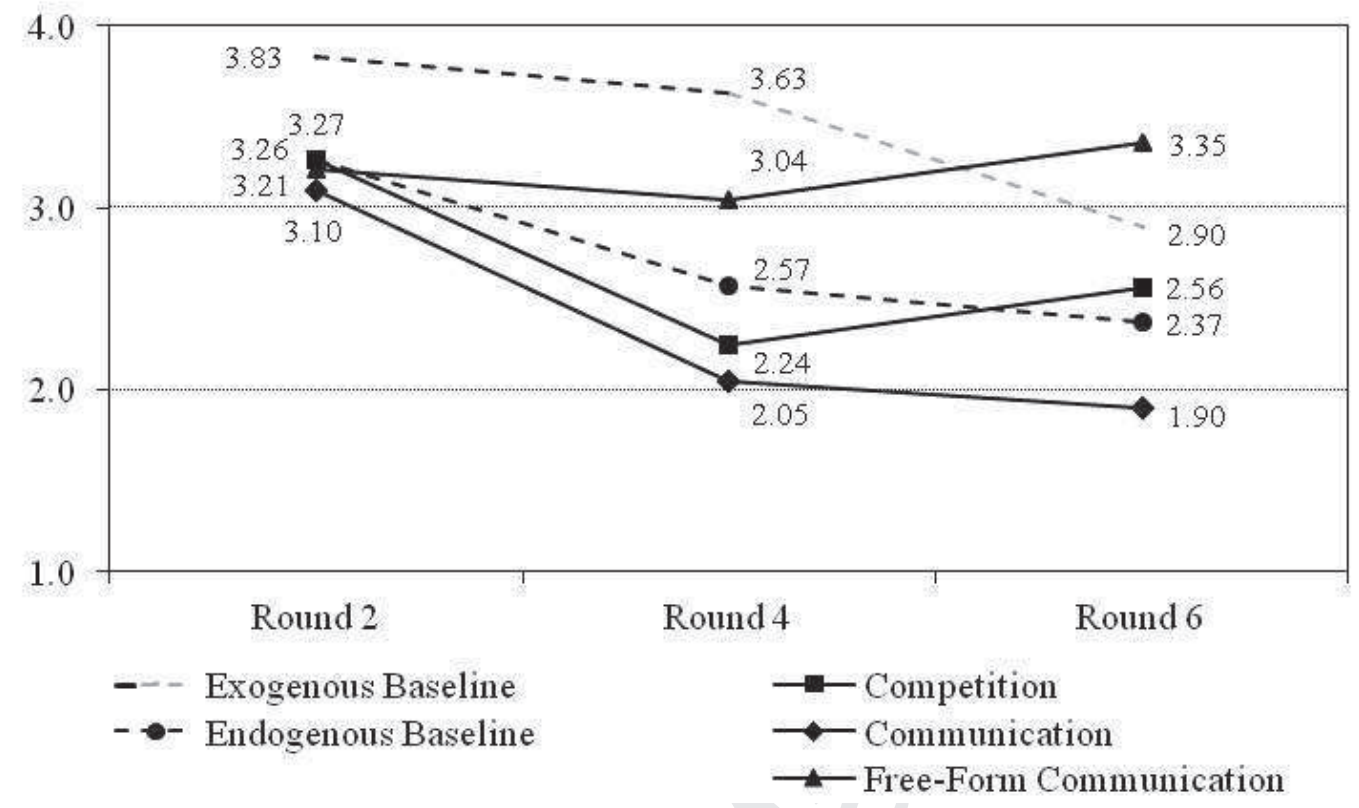

Fig. 3. Evolution of the average amount sent. 